\title{
Literature Review : Sistem Ketahanan Pangan Daerah pada Masa Pandemi Covid-19 : $A$
}

\section{Literature Review : Regional Food Security Systems during the Covid-19 Pandemic}

\author{
Muhammad Ziddan Zaelani, Qonita Rachmah*1
}

\begin{abstract}
ABSTRAK
Latar Belakang : Ketahanan pangan merupakan isu pokok dalam pemenuhan kesejahteraan masyarakat karena akan menentukan kestabilan ekonomi, sosial, dan politik dalam suatu negara. Pandemi Covid-19 membuat segala aspek kehidupan cenderung mengarah pada situasi Adaptasi Kebiasaan Baru. Sehingga, membuat perubahan situasi hampir di semua aspek kehidupan, termasuk perubahan pola rantai pasokan pangan.

Tujuan :Tujuan penelitian ini adalah mengetahui sistem ketahanan pangan yang dilakukan dibeberapa daerah yang dapat digunakan dimasa pandemi Covid-19.

Metode : Metode yang dipakai yaitu Literature Review yaitu penelitian dengan melakukan telaah terhadap beberapa artikel baik nasional maupun internasional.

Hasil : Terdapat beberapa sistem ketahanan pangan yang dapat diterapkan di masa pandemi Covid-19 sesuai dengan kondisi dimasing-masing wilayah.

Kesimpulan : Kesimpulan yang didapat adalah sistem ketahanan pangan berbeda-beda sesuai kondisi ekonomi wilayah, sumber daya manusia, kondisi geografis masing-masing wilayah terdampak.
\end{abstract}

Kata Kunci : Covid-19, Ketahanan Pangan, Pandemi, Sistem Ketahanan Pangan

\begin{abstract}
Background : Food security is a key issue in fulfilling public welfare because it will determine economic, social and political stability in a country. The Covid-19 pandemic has made all aspects of life tend to lead to a situation of New Habit Adaptation. Thus, it has made changes to situations in almost all aspects of life, including changes in food supply chain patterns.

Objective : The purpose of this study was to determine the food security system implemented in several areas that could be used during the Covid-19 pandemic.

Methods : The method used is the Literature Review, namely research by reviewing several articles, both national and international.

Results : There are several food security systems that can be applied during the Covid-19 pandemic according to the conditions in each region.

The conclusion is that the food security system varies according to the regional economic conditions, human resources, geographical conditions of each affected area.
\end{abstract}

Keyword : Covid-19, Food Security, Pandemic, Food Security System

\footnotetext{
*Koresponden:

qonita.rachmah@fkm.unair.ac.id

Qonita Rachmah

${ }^{1}$ Departemen Gizi Kesehatan, Fakultas Kesehatan Masyarakat, Universitas Airlangga Kampus C Mulyorejo, 60115, Surabaya, Jawa Timur, Indonesia
} 


\section{PENDAHULUAN}

Pangan merupakan kebutuhan dasar bagi setiap manusia untuk dapat berlangsung hidup. Dalam hal ini diperlukan ketahanan pangan untuk melangsungkan perputaran roda kehidupan bagi manusia. Ketahanan pangan merupakan proses bagi manusia untuk hidup sehat dan bekerja secara produktif untuk memenuhi kebutuhannya (Saliem and Ariani, 2016; Sawitri, 2018). Peningkatan ketahanan pangan menjadi prioritas mendasar dalam pembangunan sumber daya manusia. Hal ini dikarenakan pangan merupakan kebutuhan mendasar bagi manusia, sehingga sangat berperan penting terhadap pertumbuhan ekonomi nasional (Mulyo, Sugiyarto and Widada, 2016). Pangan juga menjadi kebutuhan primer bagi manusia untuk melanjutkan kehidupannya berdasarkan teori Abraham Masllow (Muazaroh and Subaidi, 2019).

Ketahanan pangan dapat tercapai jika setiap orang mempunyai akses dengan mudah secara fisik dan ekonomi terhadap pangan. Hal yang dimaksud adalah akses yang aman dan bermutu sesuai dengan kebutuhan gizi serta preferensinya bagi kehidupan yang aktif dan sehat (Uribe, Álvarez et al., 2010; Akrasi, Eddico and Adarkwah, 2020; Hasselberg et al., 2020). Terdapat empat dimensi utama dalam pembahasan ketahanan pangan. Pertama, adalah ketersediaan pangan yang merupakan sisi suplai dari ketahanan pangan yang ditentukan oleh tingkat produksi pangan, tingkat stok, dan selisih antara ekspor dan impor pangan. Kedua, adalah akses pangan yang diukur dengan akses secara fisik dan secara ekonomi, yang berarti bahwa secara fisik pangan harus terjangkau dalam jumlah yang mencukupi. Akses pangan secara ekonomi, yang berarti bahwa konsumen, utamanya masyarakat rawan pangan mempunyai daya beli yang cukup untuk mengakses pangan. Ketiga, adalah pemanfaatan pangan, yaitu suatu dimensi yang terkait dengan kecukupan gizi dan keamanan pangan. Keempat, adalah stabilitas, yaitu stabilitas dari dimensi pertama sampai ketiga sepanjang waktu (Gross et al., 2000; Uribe, Álvarez et al., 2010).

Sementara pada tahun 2020, dunia dihadapkan pada situasi darurat yaitu pandemi COVID-19, yaitu epidemi yang terjadi pada sekala besar hingga internasional yang mempengaruhi sejumlah negara-negara besar (Fan et al., 2019). COVID-19 merupakan penyakit yang disebabkan oleh SARS Cov-2 yang ditemukan di kota Wuhan, China pada akhir tahun 2019 dan merupakan jenis virus baru yang saat ini telah membunuh banyak manusia dan mempengaruhi seluruh sistem yang bergerak (World Health Organization, 2020). Situasi pandemi ini tidak hanya mempengaruhi situasi kesehatan, namun juga mempengaruhi sistem pangan Indonesia. Salah satu yang terpengaruh adalah sistem ketenagakerjaan di bidang pertanian diperkirakan akan mengalami kontraksi sebesar 4,87\%, sedangkan produksi pertanian domestik akan menyusut sebesar 6,2\%. Impor akan turun sebesar $17,11 \%$ dan harganya diperkirakan akan naik sebesar $1,20 \%$ dalam jangka pendek dan sebesar $2,42 \%$ dan menghambat proses ekspor pada 2022. Berkurangnya pasokan dalam negeri dan impor, kekurangan pangan dan inflasi harga makanan berpotensi besar terjadi, yang mana terdampak pada meningkatnya kemiskinan dan kekurangan gizi akibat sulitnya memenuhi kebutuhan pokok (Tim Nasional Percepatan Penanggulangan Kemiskinan, 2020). Sehingga, sangat penting untuk mengatur dan memaksimalkan intervensi ketahanan pangan masyarakat kepada populasi yang rentan didukung dengan tenaga kesehatan sebagai usaha mengurangi penyebaran wabah (FAO, 2020). Sehingga, dalam penelitian ini bertujuan untuk mengetahui sistem ketahanan pangan yang baik diterapkan dimasa pandemi Covid-19 di daerah.

\section{METODE}

Jenis penelitian menggunakan literature review. Desain penelitian digunakan metode retrospektif, prospektif dan tinjauan sistematis. Tinjauan sistematis adalah tinjauan atas pertanyaan yang dirumuskan dengan jelas yang menggunakan metode sistematis dan eksplisit untuk mengidentifikasi, memilih, dan menilai secara kritis penelitian yang relevan, dan untuk mengumpulkan dan menganalisis data dari studi yang termasuk dalam tinjauan (Vardavas dan Nikitara, 2020).

Artikel yang digunakan adalah artikel jurnal internasional dan nasional yang ditelusuri menggunakan beberapa database online: 1) Pubmed, 2) Science Direct, 3) Google Scholar. Pencarian sumber referensi atau literatur dimulai pada 10 Maret - 01 Agustus 2020. Kata kunci yang digunakan dalam pencarian istilah: ketahanan pangan "food fecurity", ekonomi gizi, strategi ketahanan pangan "food security strategy", pandemi "pandemic" dan Covid-19. Studi dimasukkan jika ada: 1) Studi manusia; 2) Diterbitkan dalam bahasa Inggris atau Indonesia; 3) Original study dan review. Penelitian ini mencari daftar referensi dari penelitian yang mencakup 89 penelitian yang diambil melalui penelusuran. Sebanyak 47 artikel di bersihkan, dan ada 5 artikel yang termasuk dalam pembahasan.

\section{HASIL DAN PEMBAHASAN}

Pandemi Covid-19 berdampak besar terhadap ketahanan pangan dan kesehatan di seluruh dunia. Sebagai langkah preventif beberapa pemerintahan daerah telah menerapkan lockdown di beberapa daerah, akibatnya akses keluar masuk bahan-bahan pokok yang mempengaruhi perkembangan pangan di daerah menjadi sulit 
(Devereux, Béné and Hoddinott, 2020; Tim Nasional Percepatan Penanggulangan Kemiskinan, 2020). Bila hal ini terus berlanjut, maka krisis ketahanan pangan dapat terjadi (Devereux, Béné and Hoddinott, 2020; FAO, 2020). Oleh karenanya memerlukan sistem ketahanan pangan yang tepat agar kebutuhan pangan dan kesehatan masyarakat tetap terpenuhi.

Berdasarkan hasil pada tabel 1 menunjukkan bahwa disetiap sistem ketahanan pangan yang digunakan oleh masing-masing wilayah berbeda sesuai kebutuhannya. Menurut (Béné, 2020) dalam penelitiannya yang dilakukan pada negara yang berpenghasilan rendah dan menengah termasuk melihat kondisi kondisi darurat yang terjadi pada negara tempat penelitian menyebutkan bahwa sistem ketahanan pangan yang baik dapat dibuat dengan cara menangkap isu terbaru, melihat tingkat rumah tangga, dan sistem kelembagaan sosial (Mulyo, Sugiyarto and Widada, 2016; Saliem and Ariani, 2016; Béné, 2020).

Sistem pertama adalah adanya kepekaan terhadap isu terkini terkait ketahanan pangan penting dilakukan oleh setiap negara dan tidak hanya berfokus pada kondisi daruratyang dialami oleh negara tersebut. Hal ini dimaksudkan agar sistem ketahanan yang dibuat oleh negara yang sedang mengalami guncangan dapat meniru sistem negara yang telah berhasil mengatasi krisis yang terjadi (Uribe, Álvarez et al., 2010; Béné, 2020). Sistem kedua membangun konsep tingkatan rumah tangga, setiap rumah tangga diajarkan untuk memiliki aset, tabungan dan akses asuransi yang dapat digunakan saat terjadi suatu musibah. Serta, pemanfaatan lembaga sosial yaitu memaksimalkan budaya saling membantu melalui lembaga sosial untuk meningkatkan perekonomian kecil dan menengah (Béné, 2020).

Penelitian yang dilakukan oleh Devereux, Béné and Hoddinott, (2020) memiliki hasil yang berbeda. Penelitiannya menyebutkan bahwa untuk menjaga kestabilan pangan memerlukan konsep 3 kerangka kerja yaitu kerangka kerja 4 pilar ketahanan pangan, kerangka kerja sistem pangan dan kerangka kerja sistem hak. Hasil penelitian tersebut menunjukkan bahwa setiap sistem ketahanan pangan harus dibuat berdsarkan ketentuan yang sudah dibuat oleh peneliti terdahulu agar tingkat kegagalan semakin rendah (Devereux, Béné and Hoddinott, 2020).

Berbeda dengan penelitian yang dilakukan oleh Shanks et al., (2020) di pemerintahan Amerika Serikat, ketahanan yang pemeritah Amerika Serikat terapkan dimasa pandemi dengan beberapa kebijakan diantaranya memberikan kelonggaran dan menyediakan cadangan makanan untuk negara bagian, sekolah menyediakan kemudahan dalam penyediaan makanan di luar kafetaria dan menggunakan sistem antar, dan pemberian dana untuk suplai gizi bagi ibu dan anak selama dua bulan pada masa darurat (Shanks et al., 2020).

Rekomendasi berdasarkan hasil penelitian yang dilakukan oleh Arouna et al., (2020) dibagi menjadi dua tahapan yaitu untuk tahap jangka pendek dan jangka panjang. Jangka pendek bagi usaha penggilingan beras, usaha dibidang pangan dan regulator bidang pangan dapat melakukan aktivitas pekerjaan dimasa pandemi dengan menggunakan protokol kesehatan agar roda perekonomian tetap berjalan dimasa pandemi (Arouna et al., 2020).

Bagi pegawai perusahaan manufaktur dan seluruh industri makanan dibuatlah sistem protokol wabah agar dapat meningkatkan produksi pangan saat pandemi. Menurut Shahbaz et al., (2020) sistem ketahanan pangan yang dapat dilakukan diantaranya melakukan manajemen keamanan pangan untuk mendeteksi Covid-19 melalui screening pada setiap pegawai, promosi personal hygiene, pengawasan pengiriman dan penerimaan barang dengan ketat, serta pembuatan SOP bagi pegawai yang terkena Covid-19 maupun sehat (Shahbaz et al., 2020).

Sehingga, berdasarkan hasil systematic review menunjukkan bahwa terdapat beberapa sistem ketahanan pangan yang dapat dilakukan oleh suatu instansi atau pemerintahan dimasa pandemi Covid-19. Model penelitian sytematic review memiliki kelemahan karena peneliti tidak dapat membuktikan secara langsung seberapa efektif masing-masing sistem ketahanan pangan yang dapat digunakan.

Kekuatan dalam penelitian model systematic review adalah terdapat beberapa referensi yang dapat digunakan untuk memperkuat argumen berdasarkan hasil penelitian sebelumnya dan tidak memerlukan biaya penelitian yang besar.

\section{KESIMPULAN}

Berdasarkan hasil penelitian diatas menunjukkan bahwa sistem ketahanan pangan perlu dilakukan tidak hanya saat terjadi pandemi atau guncangan di suatu wilayah. Namun, sistem ketahanan pangan dapat diterapkan sedini mungkin seperti yang dilakukan oleh pemerintah Amerika Serikat dengan mempersiapkan pasokan pangan sejak dini. Sistem ketahanan pangan dimasing-masing negara dan lembaga berbeda-beda sesuai dengan kebutuhan dan kejadian yang terjadi di dalam wilayah tersebut.

Disarankan bagi pemerintah terkait dalam rangka meningkatkan sistem ketahanan pangan di masa pandemi Covid-19, pemerintah dapat menerapkan sistem ATM (amati, tiru dan modifikasi) berdasarkan sistem dari beberapa negara tetangga yang dapat bertahan secara ketahanan pangan di masa pandemi Covid-19. Sistem ketahanan pangan yang cocok dilakukan di Indonesia seperti melakui swadaya masyarakat dengan sistem yang kaya membantu yang miskin. 


\section{ACKNOELEDGEMENT}

Terimakasih kepada semua pihak yang membantu kami dalam melakukan proses penyusunan artikel ini hingga sampai pada tahap publis, kami berharap semoga ilmu yang dapat kami berikan melalui artikel ini dapat bermanfaat bagi para pembaca

\section{REFERENSI}

Akrasi, R. O., Eddico, P. N. and Adarkwah, R. (2020) Income Diversification Strategies and Household Food Security among Rice Farmers : Pointers to Note in the North Tongu District of Ghana , Journal Global Food Security, 8(3), pp. 77-88. doi: 10.12691/jfs-8-3-1.

Arouna, A. Soullier, G. del Villar, P M. Demont, M. (2020) Policy options for mitigating impacts of COVID-19 on domestic rice value chains and food security in West Africa, Global Food Security. Elsevier B.V., 26, p. 100405. doi: 10.1016/j.gfs.2020.100405

Béné, C. (2020) Resilience of local food systems and links to food security - A review of some important concepts in the context of COVID-19 and other shocks, Food Security. Food Security, 12(4), pp. 805822. doi: 10.1007/s12571-020-01076-1.

Devereux, S., Béné, C. and Hoddinott, J. (2020) Conceptualising COVID-19's impacts on household food security, Food Security. Food Security, 12(4), pp. 769-772. doi: 10.1007/s12571-020-01085-0.

Fan, Y. Zhao, K. Shi, Z. Zhou, P. (2019) Bat coronaviruses in China, Viruses, 11(3), pp. 27-32. doi: $10.3390 / \mathrm{v} 11030210$.

FAO (2020) Addressing the impacts of COVID-19 in food crises | April-December 2020, Addressing the impacts of COVID-19 in food crises | April-December 2020,2019 (December) .doi:10.4060/ca8497en.

Gross, R. Schoeneberger, H. Pfeifer, H. Joachim, H. (2000) The four dimensions of food and nutrition security: definitions and concepts, SCN News, pp. 1-17. Available at: http://www.ieham.org/html/docs/The_Four_Dimensions_FNS_Definitions_and_Concepts.pdf.

Hasselberg, A. E. Aakre, I. Scholtens, J. Overa, R. Kolding, J. Bank, M,S. Atter, A. Kjellvold, M. (2020) Fish for food and nutrition security in Ghana: Challenges and opportunities, Global Food Security. Elsevier B.V., 26(April), p. 100380. doi: 10.1016/j.gfs.2020.100380.

Muazaroh, S. and Subaidi (2019) Kebutuhan Manusia dalam Pemikiran Abraham Maslow, Al-Mazahib, 7(1), pp. 17-33. Available at: ejournal.uin-suka.ac.id.

Mulyo, J. H., Sugiyarto, S. and Widada, A. W. (2016) Ketahanan Dan Kemandirian Pangan Rumah Tangga Tani Daerah Marginal Di Kabupaten Bojonegoro, Agro Ekonomi, 26(2), p. 121.doi:10.22146/agroekonomi.17265.

Saliem, H. P. and Ariani, M. (2016) Ketahanan Pangan, Konsep, Pengukuran dan Strategi, Forum penelitian Agro Ekonomi, 20(1), p. 12. doi: 10.21082/fae.v20n1.2002.12-24.

Sawitri, N. (2018) Pelaksanaan Program Perbaikan Gizi Masyarakat Oleh Dinas Kesehatan Kota Pekanbaru, Jom Fisip, 5(1), pp. 1-15.

Shahbaz, M. Bilal, M. Akhlaq, M. Moiz, A. Zubair, S. Iqbal, H. M. N. (2020) Strategic measures for food processing and manufacturing facilities to combat coronavirus pandemic (COVID-19), Journal of Pure and Applied Microbiology, 14(2), pp. 1087-1094. doi: 10.22207/JPAM.14.2.01.

Shanks, C. B. Hingle, M. D. Parks, C. A. Yaroch, A. L. (2020) The COVID-19 Pandemic: A Watershed Moment to Strengthen Food Security Across the US Food System, American journal of public health, 110(8), pp. 1133-1134. doi: 10.2105/AJPH.2020.305760.

Tim Nasional Percepatan Penanggulangan Kemiskinan (2020) Ketahanan Pangan di Tengah Pandemi Covid-19, Bhirawa Online.

Uribe, Álvarez, M. C. (2010) An Introduction to the Basic Concepts of Food Security, Social Indicators Research, 95(1), pp. 215-230. doi: 10.1007/s11524-010-9491-z.

World Health Organization (2020) Coronavirus Diseases -19, W.H.O Publication. Available at: https://www.who.int/indonesia/news/novel-coronavirus (Accessed: 11 June 2020). 
Tabel 1. Hasil Studi Sistem Ketahanan Pangan Saat Pandemi

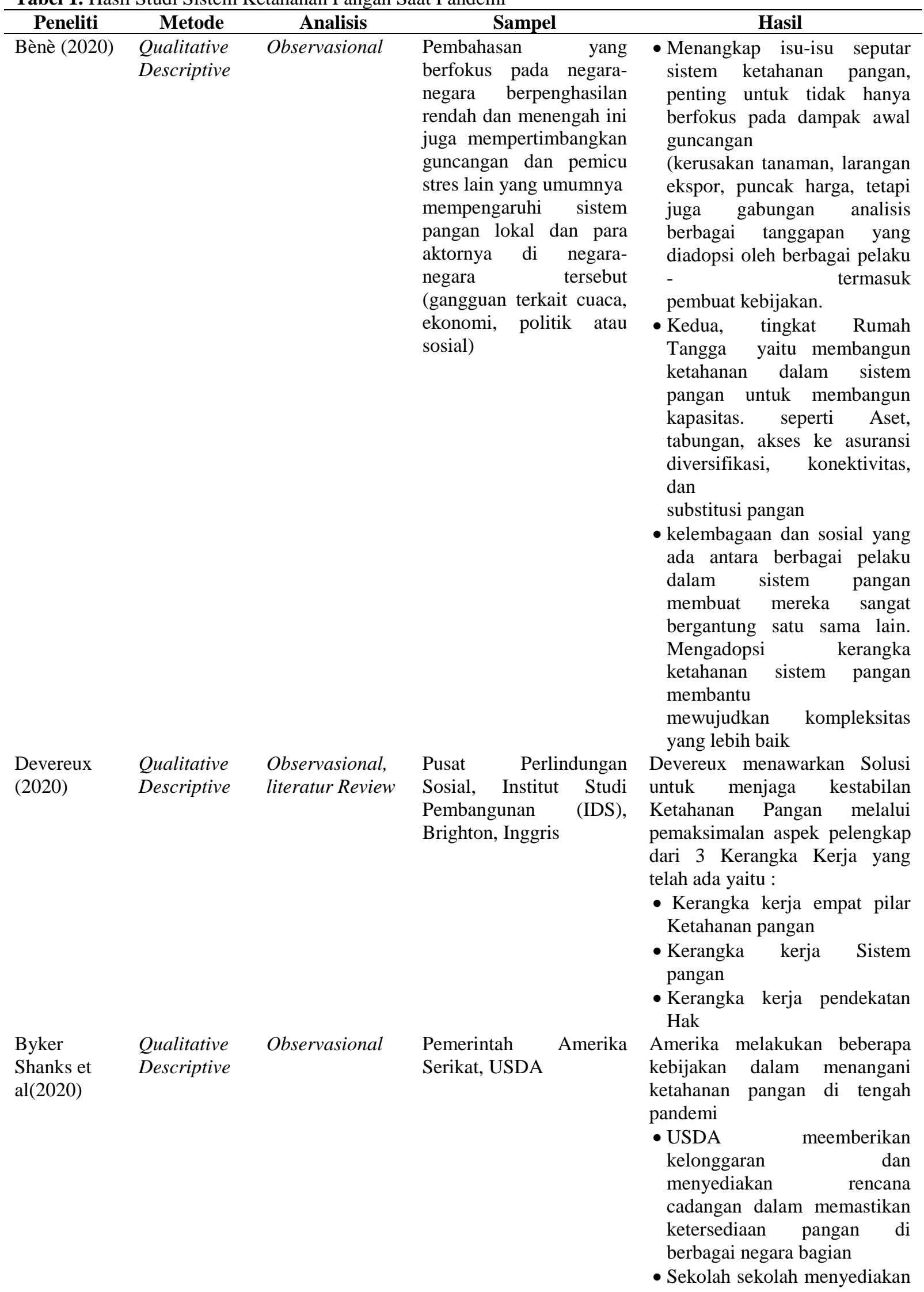




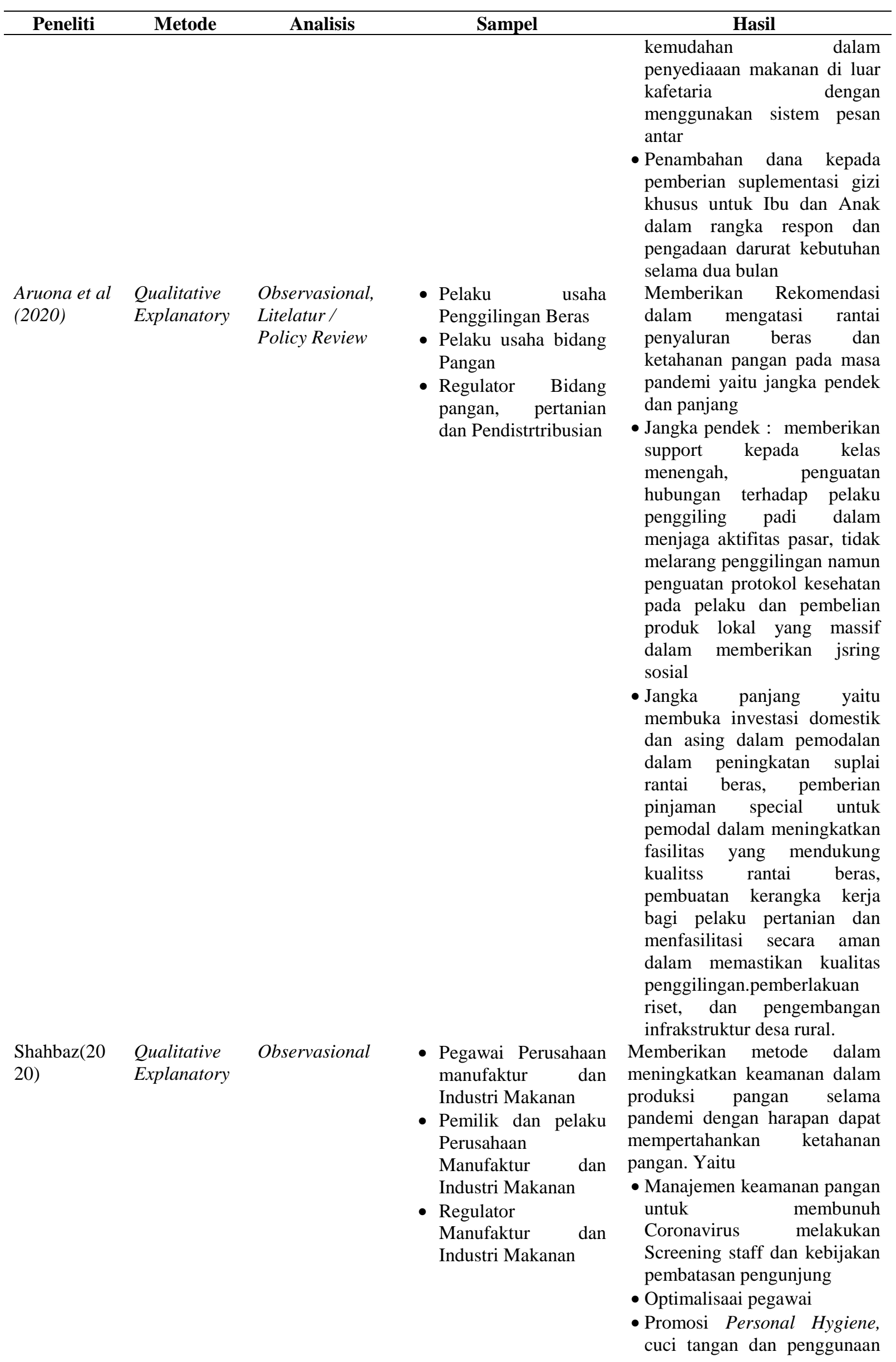


297 Media Gizi Kesmas, Vol. 10. No. 2, Desember 2021: Halaman : 291-297

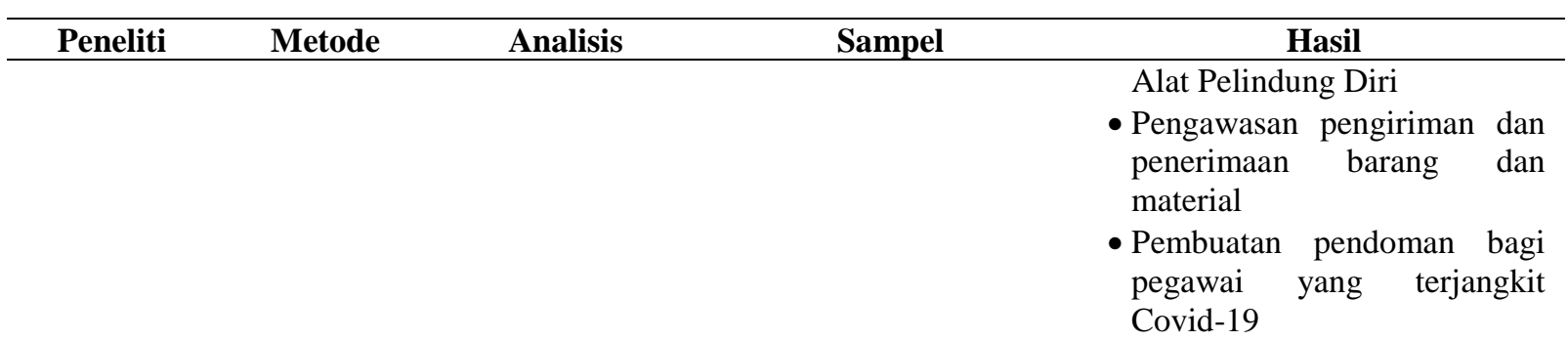

